\title{
Recombinant human thyrotropin preparation for adjuvant radioiodine treatment in children and adolescents with differentiated thyroid
} cancer

\author{
Daria Handkiewicz-Junak, Tomasz Gawlik, Jozef Rozkosz, Zbigniew Puch, \\ Barbara Michalik, Elżbieta Gubala, Jolanta Krajewska, Aneta Kluczewska and \\ Barbara Jarzab \\ Department of Nuclear Medicine and Endocrine Oncology, Maria Sklodowska-Curie Memorial Institute and \\ Centre of Oncology, Gliwice Branch, Wybrzeze Armii Krajowej 14, 44-100 Gliwice, Poland
}

\begin{abstract}
Aim: Although recombinant human thyrotropin (rhTSH) is widely used in treating differentiated thyroid cancer (DTC), almost all clinical investigation has been in adults. The aim of our retrospective study was to evaluate outcomes of adjuvant, rhTSH-aided radioiodine treatment in children/adolescents with DTC and to compare them to ${ }^{131}$ I therapy during L-thyroxin withdrawal (THW).

Methods: Patients with the diagnosis of DTC who were $\leq 18$ years of age and had no signs of persistent disease at the time of ${ }^{131}$ I treatment were included; 48 patients were treated after rhTSH (rhTSH group) and 82 after THW group. The median time of follow-up after therapy was 67 months and was longer in the THW group (99 vs 43 months, $P<0.05$ ).

Results: On the day of ${ }^{131} \mathrm{I}$ administration, all but one patient had TSH levels above $25 \mu \mathrm{IU} / \mathrm{ml}$. Peak TSH concentration was significantly higher in the rhTSH group $(152 \mu \mathrm{lU} / \mathrm{ml}$ vs $91 \mu \mathrm{lU} / \mathrm{ml})$. Similarly, the thyroglobulin concentration was higher in the $\mathrm{rhTSH}$ group $(9.7 \mathrm{ng} / \mathrm{ml}$ vs $1.8 \mathrm{ng} / \mathrm{ml})$. No side effects requiring medical intervention were recorded after rhTSH administration. The evaluation of disease outcomes during TSH stimulation (6-18 months after ${ }^{131}$ I treatment) revealed equal rates of thyroid ablation (71\%) in both groups. During subsequent follow-up, five patients showed recurrence $(P>0.05)$. Conclusions: In children/adolescents, rhTSH-aided adjuvant radioiodine treatment is associated with rates of remnant ablation and short-term recurrence similar to THW. As this preparation has several advantages over THW, rhTSH may become the preferred method of TSH stimulation once studies of long-term outcomes show non-inferiority to THW in this age group.

European Journal of

Endocrinology

(2015) 173, 873-881
\end{abstract}

\section{Introduction}

Initial treatment for patients with differentiated thyroid cancer (DTC) is total or near-total thyroidectomy, which is often followed by adjuvant radioactive iodine $\left({ }^{131} \mathrm{I}\right)$ treatment $(1,2)$. The rationale for adjuvant radioiodine treatment is to decrease the risk of clinical tumour recurrence $(3,4)$ and improve the sensitivity and specificity of follow-up testing with serum thyroglobulin measurement and radioiodine scanning (5). To promote radioiodine uptake in the remaining normal thyroid and cancer cells, treatment is performed after stimulation of ${ }^{131} \mathrm{I}$ uptake either with endogenous thyroid stimulating hormone (TSH) (after withdrawal of L-thyroxin) or exogenous stimulation with recombinant human thyrotropin (rhTSH). rhTSH enables patients to attain the TSH elevation necessary to optimize radioiodine treatment while sparing thyroidectomised patients hypothyroid morbidity (6) and extra-thyroidal radiation exposure $(7,8)$. rhTSH-aided adjuvant radioiodine (c) 2015 European Society of Endocrinology Printed in Great Britain
Published by Bioscientifica Ltd. 
treatment has been proven a safe and effective therapy in adult DTC patients.

Most clinical studies and all regulatory approvals of rhTSH have been done in adults but not in children or adolescents (9). However, the potential of rhTSH-aided radioiodine therapy to decrease extra-thyroidal radiation exposure and hypothyroid morbidity is extremely important for the developing organism of young patients. Reports on the effectiveness and safety of ${ }^{131} \mathrm{I}$ are not numerous, and only a few case reports and one small, retrospective study involving paediatric patients treated with rhTSH-aided adjuvant ${ }^{131}$ I have been published so far $(10,11,12,13)$.

Beginning in 1999, our centre started to offer rhTSHaided radioiodine treatment as an adjunct to thyroid surgery or treatment of locoregional/metastatic DTC, first during an 'off-label' or 'compassionate use' program and subsequently on a regular basis. The decision of rhTSH or L-thyroxin withdrawal (THW) preparation for radioiodine treatment was left to the discretion of the treating physician and the patient. All radioiodine treatments, regardless of the method of preparation, were performed by the same nuclear medicine group following a standard protocol.

Herein, we have taken the opportunity to retrospectively review these two procedures and their clinical outcomes in children/adolescents diagnosed with DTC and treated with radioiodine as an adjunct to neck surgery. For the purpose of this study, adjuvant radioiodine treatment was defined as ${ }^{131}$ I treatment in DTC patients in whom primary tumour and metastatic lymph nodes were removed during primary neck surgery.

\section{Subjects and methods}

\section{Patients}

We retrospectively reviewed charts of DTC patients who were treated with radioactive iodine during the years 2000-2010. We searched for patients who were 18 years of age or younger during ${ }^{131}$ I treatment and had no signs of locoregional or distant disease on clinical or imaging examinations, confirming that the radioiodine treatment was an adjunct to the surgical treatment. Initially we identified 163 patients who were 18 years of age or younger at the time of their first ${ }^{131}$ I treatment; 130 $(80 \%)$ of these children/adolescents fulfilled our inclusion criteria, e.g., had no clinical signs of persistent thyroid cancer at the time of ${ }^{131}$ I treatment. The data collected from medical charts included findings at diagnosis, surgery, ${ }^{131} \mathrm{I}$ therapy, and outcome. The institutional ethics board approved this retrospective study on childhood thyroid cancer, and the requirement to obtain informed consent was waived.

In 48 (37\%) patients, ${ }^{131}$ I therapy was performed after rhTSH stimulation (the rhTSH group) and in 82 (63\%) after thyroid hormone withdrawal (the THW group). During the study period, the proportion of patients treated with rhTSH increased over time, and by 2008 , the number of rhTSH procedures exceeded the number of endogenous TSH stimulation procedures.

The median age during ${ }^{131}$ I therapy was 15.6 years (range 6-18) and the majority of patients were girls. Before radioactive iodine therapy, all patients but one were treated with total/near total thyroidectomy. There were no significant intergroup differences in age, extent of surgery, histopathology, or primary tumour stage. All patients were free of persistent DTC, as confirmed by neck ultrasound, radiological, and scintigraphic examinations, during ${ }^{131}$ I therapy. The average interval between thyroid surgery and radioiodine therapy was 77 days, and this was significantly shorter in the rhTSH group (61 vs 88 days, $P<0.005)$. Detailed characteristics of the study groups are provided in Table 1.

\section{Radioiodine treatment procedure}

Patients were treated according to a standard protocol with one- or two-stage total/near total thyroidectomy and adjuvant radioiodine therapy. In one patient, according to the surgeon, a subtotal thyroidectomy was performed, but on ultrasound examination thyroid remnants volume were $1.8 \mathrm{ml}$ so reoperation was not recommended. The median interval between the last surgical intervention and ${ }^{131}$ I treatment was 77 days; however, in 10 cases it was more than 12 months, usually due to delayed referral for radioiodine treatment. Patients were treated with ${ }^{131}$ I after THW or rhTSH stimulation at the discretion of the treating physician and after a discussion with the patient and his or her parents. Thyroid hormone withdrawal lasted for 4 weeks, or 2 weeks in case of triiodothyronine $\left(\mathrm{T}_{3}\right)$ pretreatment. Recombinant human TSH was administered according to a standard regimen (for details, see Supplementary Figure 1, see section on supplementary data given at the end of this article) and its application was approved by the local ethics committee.

Radioactive iodine activity was adjusted to the child's age. Children $<12$ years old were administered 74-92.5 MBq/kg body weight, and older children had fixed activities of 2.2-3.7 GBq. According to standard 
Table 1 Comparison of rhTSH and non-THW groups.

\begin{tabular}{l} 
Clinical characteristics \\
\hline Female \\
Age at DTC diagnosis (years) \\
Mean \\
$<10$ years \\
Extent of operation \\
Total/near total thyroidectomy \\
DTC histopathology \\
Papillary \\
Papillary follicular variant \\
Papillary (other variants) \\
Follicular \\
Primary tumour (UICC 2010) \\
T1 \\
T2 \\
T3 \\
T4 \\
Tx \\
Lymph nodes status \\
N0 \\
N1a \\
N1b \\
No lymph nodes dissection \\
Time from last thyroid surgery to ${ }^{131}$ I \\
therapy (median; days) \\
131 I activity in GBq (median) \\
BMI (kg/m²; median) \\
131 I activity/BMI \\
\end{tabular}

\begin{tabular}{|c|c|}
\hline All $(n=130)$ & THW group $(n=82)$ \\
\hline $99(76 \%)$ & $62(76 \%)$ \\
\hline$\frac{15.6 \pm 2.6}{6}$ & $\begin{array}{l}15.5 \pm 2.6 \\
4(5 \%)\end{array}$ \\
\hline $130(99 \%)$ & $83(100 \%)$ \\
\hline $85(65 \%)$ & $54(66 \%)$ \\
\hline $31(24 \%)$ & $21(26 \%)$ \\
\hline $7(5 \%)$ & $2(2 \%)$ \\
\hline $7(5 \%)$ & $5(6 \%)$ \\
\hline $60(46 \%)$ & $40(49 \%)$ \\
\hline $31(24 \%)$ & $18(22 \%)$ \\
\hline $24(19 \%)$ & $13(16 \%)$ \\
\hline $\mathrm{x}$ & $\mathrm{x}$ \\
\hline $15(12 \%)$ & $11(13 \%)$ \\
\hline $33(25 \%)$ & $20(24 \%)$ \\
\hline $26(20 \%)$ & $16(19 \%)$ \\
\hline $51(39 \%)$ & $32(39 \%)$ \\
\hline $20(15 \%)$ & $14(17 \%)$ \\
\hline $77(21-725)$ & $88(7-725)$ \\
\hline $3.7(2.2-4.0)$ & $3.7(2.2-4.0)$ \\
\hline $20.9(14.2-39.4)$ & $21.0(14.2-39.4)$ \\
\hline $2.9(1.8-3.2)$ & $2.9(1.8-3.2)$ \\
\hline
\end{tabular}

\begin{tabular}{|c|c|}
\hline rhTSH group $(n=48)$ & $\boldsymbol{P}$ \\
\hline $37(77 \%)$ & NS \\
\hline $\begin{array}{l}15.7 \pm 2.6 \\
2(4 \%)\end{array}$ & $\begin{array}{l}\text { NS } \\
\text { NS }\end{array}$ \\
\hline $47(98 \%)$ & NS \\
\hline $\begin{array}{c}31(65 \%) \\
10(21 \%) \\
5(10 \%) \\
2(4 \%)\end{array}$ & NS \\
\hline $\begin{array}{l}20(42 \%) \\
13(27 \%) \\
11(23 \%)\end{array}$ & $\begin{array}{l}\text { NS } \\
\text { NS } \\
\text { NS }\end{array}$ \\
\hline $\begin{array}{l}x \\
4(8 \%)\end{array}$ & NS \\
\hline $\begin{array}{c}13(27 \%) \\
10(21 \%) \\
19(40 \%) \\
6(12 \%) \\
61(21-197)\end{array}$ & $\begin{array}{c}\text { NS } \\
\text { NS } \\
\text { NS } \\
\text { NS } \\
0.005\end{array}$ \\
\hline $\begin{array}{c}3.7(2.2-3.7) \\
20.8(14.4-31.6) \\
2.9(1.8-3.0)\end{array}$ & $\begin{array}{l}\text { NS } \\
\text { NS } \\
\text { NS }\end{array}$ \\
\hline
\end{tabular}

NS, not significant.

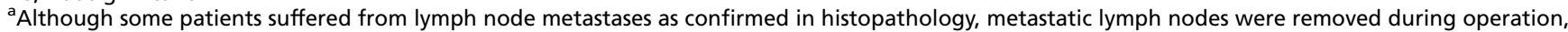
and during radioiodine treatment, none of the patients suffered from persistent, macroscopic disease.

institutional practice, all patients were hospitalized in a radionuclide therapy ward with full radiation protection for at least 3 days after radioiodine administration and then discharged when the radiation dose rate at $1 \mathrm{~m}$ was $<20 \mu \mathrm{Sv} / \mathrm{h}$. Post-therapy whole body scans (WBS) and, when required, spot or tomography imaging were performed $72 \mathrm{~h}$ after ${ }^{131} \mathrm{I}$ treatment with a dual-head gamma camera (Multispect 2 or E. Cam-Duet, Siemens, Erlangen, Germany) equipped with parallel high-energy collimators.

\section{Patient follow-up}

After radioiodine treatment, all patients were advised to keep TSH levels within 0.1-0.4 $\mu \mathrm{IU} / \mathrm{ml}$. Stimulated thyroglobulin (Tg) and ${ }^{131}$ I WBS were performed 6-18 months after radioiodine treatment to assess the efficacy of the radioiodine treatment. Thereafter, all patients were followed-up with neck ultrasound, $\mathrm{TSH}$, and $\mathrm{Tg}$ and $\mathrm{Tg}$ antibodies (TgAb) at 6- to 18-month intervals.

For thyroglobulin evaluation, only patients with negative thyroglobulin antibodies were included.
Thyroglobulin concentrations were measured with an immunoradiometric (IRMA) assay DYNOtest Tg-S (Brahms; analytical sensitivity $0.05 \mathrm{ng} / \mathrm{ml}$, functional sensitivity $0.3 \mathrm{ng} / \mathrm{ml}$ ) until 2004. From January 2004 through May 2009, thyroglobulin was evaluated with a Timed Resolved Amplified Cryptate Emission assay (BRAHMS hTg KRYPTOR; analytical sensitivity $0.17 \mathrm{ng} / \mathrm{ml}$, functional sensitivity $0.5 \mathrm{ng} / \mathrm{ml}$ ) and, thereafter, with an Electrochemiluminescent Immunoassay (Roche Diagnostic, analytical sensitivity $0.1 \mathrm{ng} / \mathrm{ml}$, functional sensitivity $1 \mathrm{ng} / \mathrm{ml}$ ). Patients were considered as thyroglobulin-antibody free unless $\mathrm{Tg}$ recovery was $<70 \%$ or $>130 \%$ (institutional cut-off level; measurements performed until August 2006) or the $\mathrm{TgAb}$ concentration was detectable $(<10 \mathrm{IU} / \mathrm{ml}$, measurement performed from September 2006; (BRAHMS TRACE assay; analytic sensitivity $10 \mathrm{IU} / \mathrm{ml}$, functional sensitivity $33 \mathrm{IU} / \mathrm{ml}$ ).

\section{Definitions of treatment outcomes}

For TgAb-negative patients, the following criteria were used to diagnose a complete remission of DTC: during TSH 
stimulation: Tg below $2 \mathrm{ng} / \mathrm{ml}$, no pathological (thyroid bed or metastases) uptake of ${ }^{131}$ I on WBS, and no signs of disease on neck ultrasound or other diagnostic examinations; during L-thyroxin treatment, patients were diseasefree if $\mathrm{Tg}$ was below $1 \mathrm{ng} / \mathrm{ml}$ and there was no structural recurrence on neck ultrasound or radiological examinations. TgAb-positive DTC patients were diagnosed with a complete remission if there was no pathological (thyroid bed or metastases) uptake of ${ }^{131}$ I on WBS and there were no signs of disease on neck ultrasound or other diagnostic examinations.

\section{Statistical analysis}

Descriptive analyses were performed to calculate means/ medians depending on data distribution. Quantitative data with a normal distribution were compared with the Student's $t$-test, while non-normally distributed data were compared using Wilcoxon signed rank tests. Categorical data or frequencies of events were compared using the Pearson $\chi^{2}$ or Fisher exact test (if the group number was less than 10). A $P$ value $<0.05$ was deemed significant. Analyses were performed using Statistica for Windows version 5.5PL (Statsoft, Tulsa, OK, USA). Percent/ages were rounded to the nearest whole number; therefore, totals exceed $100 \%$ for some parameters.

\section{Results}

\section{Radioactive iodine treatment}

Administered activity of ${ }^{131} \mathrm{I}$ did not differ between the rhTSH and THW group. On the day of ${ }^{131}$ I administration, all but one patient (in the THW group) had a TSH level above $25 \mu \mathrm{IU} / \mathrm{ml}$. However, in the rhTSH group, the peak TSH concentration was significantly higher than in the THW group (Fig. 1). Peak TSH concentration on the day 3 of rhTSH stimulation showed a weak but significant inverse correlation with BMI (Supplementary Figure 2, see section on supplementary data given at the end of this article); no such correlation was seen in the THW group. In 17 patients $(50 \%$ of the patients evaluated on day 6 of stimulation), TSH returned to normal limits by day 6 of stimulation (Fig. 1) and was higher than $10 \mu \mathrm{IU} / \mathrm{ml}$ in only 4 patients.

Thyroglobulin antibodies were detected in 35 (23\%) patients, either through direct TgAb measurement $(n=31)$ or Tg recovery test $(n=4)$. Thyroglobulin antibodies were more frequent in the rhTSH group (Fig. 2). After excluding patients with positive Tg antibodies, serum thyroglobulin

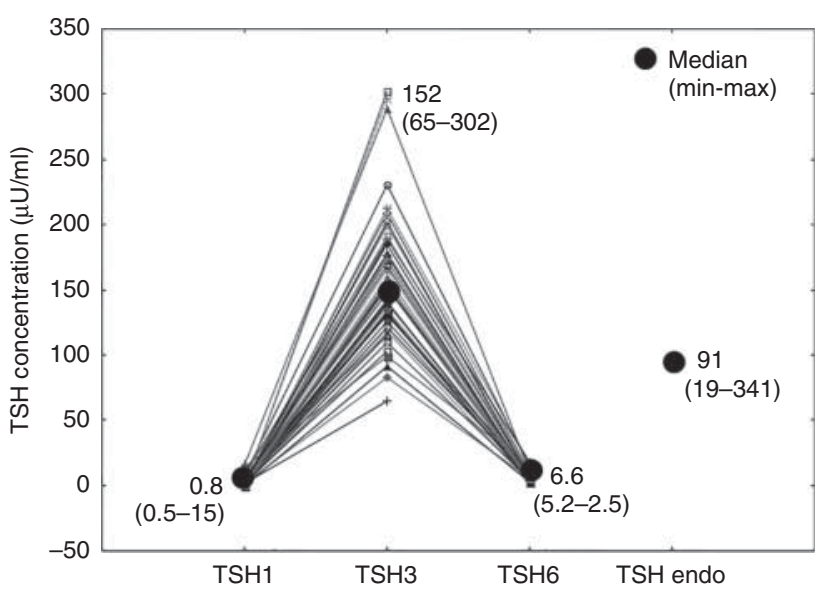

\section{Figure 1}

TSH concentration during rhTSH stimulation (day 1, 3, and 6) and thyroid hormone withdrawal. TSH1, TSH2, and TSH3-days of rhTSH stimulation (rhTSH group). TSH endo-TSH during endogenous TSH stimulation (THW group). TSH1 vs TSH3 vs TSH6, $P<0.05$. TSH3 vs TSH endo, $P<0.05$.

concentration increased as a result of rhTSH stimulation and was the highest on day 6 of rhTSH stimulation (Fig. 3). Thyroglobulin in the THW group (measurements performed on the day of radioiodine treatment) was significantly lower than on day 6 of rhTSH stimulation but higher than on day 3 of rhTSH stimulation (Fig. 3).

Three days (or $72 \mathrm{~h}$ ) after radioiodine administration, the radiation dose rate at $1 \mathrm{~m}$ was measured. The median radiation dose was $7 \mu \mathrm{Sv} / \mathrm{h}$ in the whole group of patients. There was a tendency for a higher dose rate in the THW group (median: THW $8 \mu \mathrm{Sv} / \mathrm{h}$; rhTSH $6 \mu \mathrm{Sv} / \mathrm{h}$ ); however, the difference was of borderline significance $(P=0.07)$.

No side effects were recorded in medical charts after rhTSH administration. There was no increase in the free thyroid hormone ( $\mathrm{fT}_{3}$ and $\mathrm{fT}_{4}$ ) concentration in the rhTSH treated group (Supplementary Figure 3, see section on supplementary data given at the end of this article).

\section{Post ${ }^{131}$ I treatment evaluation during TSH stimulation}

The median time between radioactive iodine treatment and evaluation of its outcome during TSH stimulation was 12 months. For most of the patients (105 (88\%)), diagnostic examinations were performed after thyroid hormone withdrawal. In 15 (12\%), rhTSH was used. Five patients from the rhTSH and five from the THW group were followed-up only while on L-thyroxin therapy and were not included in this sub-analysis. 


\begin{tabular}{|c|c|c|c|}
\hline & $\begin{array}{r}\text { Direct } \\
\text { Negative }\end{array}$ & $\begin{array}{l}\text { TgAb } \\
\text { Positive }\end{array}$ & $\begin{array}{l}\text { Tg recovery test } \\
\text { Negative Positive }\end{array}$ \\
\hline \multirow[t]{3}{*}{$\begin{array}{l}\text { (A) }{ }^{31} 1 \text { treatment } \\
(n=129)\end{array}$} & rhTSH & 26 & \\
\hline & $P<0.004$ & & \\
\hline & THW & 5 & 59 \\
\hline \multirow{3}{*}{$\begin{array}{l}\text { (B) Follow-up } \\
\text { under TSH stimulation } \\
(n=117)\end{array}$} & ritSH & 20 & 2 \\
\hline & $P$-ns & & ns \\
\hline & THW & 8 & 44 \\
\hline \multirow{2}{*}{$\begin{array}{l}\text { (C) Last } \\
\text { estimation } \\
(n=130)\end{array}$} & 32 & 16 & \\
\hline & $P$-ns & & $P$-ns \\
\hline THW & 43 & 36 & \\
\hline
\end{tabular}

\section{Figure 2}

Thyroglobulin antibody (TgAb) concentration during (A) radioiodine treatment, $(B)$ follow-up during TSH stimulation, and (C) last follow-up. Thyroglobulin was evaluated either by directly measuring $\mathrm{TgAb}$ or with a thyroglobulin recovery test. Cut-off levels are provided in the text. TSH stimulation data on TgAb status during ${ }^{131}$ I treatment and during follow-up were not available for one and three patients respectively. Please note that during ${ }^{131}$ I treatment there were significantly more positive TgAb results in the rhTSH group than in the THW group. However, during follow-up the difference was insignificant.

From the 120 evaluated ${ }^{131}$ I WBS, thyroid remnant ablation was confirmed in 99 (83\%) patients, and there was no difference in the ablation rate between groups previously treated with exogenous or endogenous TSH stimulation (Table 2).

Stimulated serum thyroglobulin and TgAb concentration was available for 117 out of 120 evaluated patients (97.5\%); 84 (72\%) were considered thyroglobulin antibody negative (Fig. 2). At that time, there was no difference in Tg antibody negativity between the rhTSH and thyroid THW groups. Considering patients without interfering thyroglobulin antibodies, $75 \%$ had thyroglobulin concentration below $1 \mathrm{ng} / \mathrm{ml}$; this number increased to $83 \%$ for a Tg cut-off level below $2 \mathrm{ng} / \mathrm{ml}$. The proportion of patents with low Tg was similar in the rhTSH and THW groups (Table 2).

Overall complete remission (scintigraphic and biochemical) was confirmed in 83 (71\%) patients, and there was no difference in remission rates between the THW and rhTSH groups. Similar rates of complete remission were observed when only patients without $\mathrm{TgAb}$ were analysed (Table 2).

The number of patients referred for ${ }^{131}$ I retreatment did not differ between the groups; 17 (22\%) and 10 (23\%) patients from the THW and rhTSH group, respectively, were referred for second radioiodine therapy (Table 3). The majority of retreatments were performed due to persistent radioiodine uptake in the thyroid bed or persistently increased Tg concentration. Six patients were retreated due to unequivocal results of WBS (suspicious uptake in the surgical bed after neck lymphadenectomy or in the upper mediastinum) during the first adjuvant radioiodine treatment. In two patients, who were retreated due to increasing $\mathrm{Tg}$ concentration, WBSs revealed lung metastases.

\section{Follow-up during L-thyroxin treatment}

The median time of follow-up from the time of ${ }^{131}$ I therapy to the last observation was 67 (12-153) months and was significantly longer in the THW group (99 vs 43 months, $P<0.05)$. During that time, five $(3.8 \%)$ patients were diagnosed with structural DTC recurrence. Two patients were diagnosed with neck lymph node metastases (both in the THW group) 6 and 8 years after radioiodine treatment. Three other patients were diagnosed with lung metastases on WBSs performed after the second course of radioiodine therapy (one in the rhTSH and two in the THW group). In two patients, the second radioiodine treatment was performed 5-7 months after the first ${ }^{131}$ I therapy. The indications for therapy were a persistent uptake in the thyroid bed in one case and persistent Tg elevation in the second. In the third patient, lung recurrence was diagnosed 6 years after radioiodine treatment.

In four other patients (one in the THW and three in the rhTSH group), there was a persistent elevation of thyroglobulin levels (in three of them, there was also an

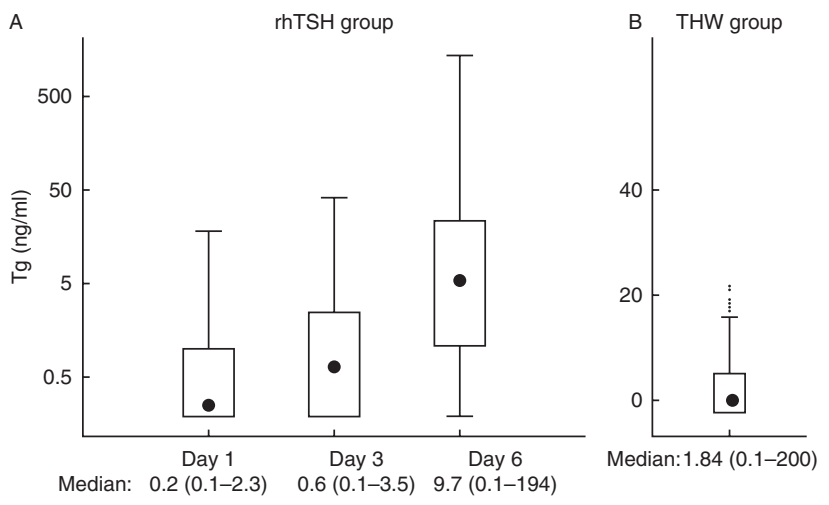

\section{Figure 3}

Stimulated thyroglobulin concentration in the $\mathrm{rhTSH}(\mathrm{A})$ and THW (B) groups. Day 1 vs day 3 vs day $6, P<0.05$. Group $A$ (day 3 and 6) vs $B, P<0.05$. 
Table 2 Scintigraphic and biochemical evaluation (during TSH stimulation) performed 6-18 months after ${ }^{131}$ I therapy.

\begin{tabular}{l}
\hline \\
\hline Scintigraphy \\
No radioiodine uptake $(n=120)$ \\
Persistent uptake in thyroid bed \\
Biochemical evaluation ${ }^{\mathrm{a}}$ \\
Tg concentration $(n=84)$ \\
$<2 \mathrm{ng} / \mathrm{ml}$ \\
$\leq 1 \mathrm{ng} / \mathrm{ml}$ \\
Complete remission (scintigraphic and biochemical) \\
All patients $(n=117)$ \\
Patients with negative thyroglobulin antibody $(n=84)$
\end{tabular}

\begin{tabular}{c}
\hline All $(n=120)$ \\
\hline $99(83 \%)$ \\
$21(17.5 \%)$ \\
\\
$70 / 84(83 \%)$ \\
$63 / 84(75 \%)$ \\
$83 / 117(71 \%)$ \\
$62 / 84(74 \%)$ \\
\hline
\end{tabular}

THW group $(n=77)$
$63(82 \%)$
$14(18 \%)$

$53 / 62(85 \%)$
$47 / 62(76 \%)$
$53 / 75(71 \%)$
$46 / 62(74 \%)$

rhTSH group $(n=43)$
$36(84 \%)$
$7(16 \%)$

$\boldsymbol{P}$

NS

$17 / 22(77 \%)$

$16 / 22(73 \%)$

NS

$30 / 42(71 \%)$

$16 / 22(72 \%)$

NS, not significant.

${ }^{a}$ Only patients with negative $\operatorname{TgAb}$ were included.

increase in $\mathrm{TgAb}$ concentration). Imaging studies including positron emission tomography with 18-FDG were negative for disease recurrence in these patients.

None of the patients developed a second neoplasm during the follow-up period.

\section{Discussion}

According to the American Thyroid Association (ATA) guidelines (2) and the European Consensus for the management of DTC (14), adjuvant radioiodine treatment is indicated for patients with large thyroid tumours, gross extra-thyroid extension, lymph node metastases, or other high-risk features. These indications are based on clinical studies showing reduced recurrence rate and mortality from DTC after ${ }^{131}$ I treatment $(3,4)$.

Although children/adolescents often present with advanced disease, due to their low mortality rate they are considered low risk. Hence, radioiodine treatment in this young group of DTC patients is questioned by some $(15,16)$ but supported by other authors $(17,18,19,20)$, who showed a decreased risk of DTC recurrence after radioiodine treatment. In the recent ATA Management Guidelines for Children with Thyroid Nodules and Differentiated Thyroid Cancer (9), ${ }^{131}$ I is indicated for treatment of iodine-avid persistent locoregional or nodal disease that cannot be resected as well as known or presumed iodineavid distant metastases. One of the major issues raised by opponents of adjuvant radioiodine treatment in children/adolescents is the risk of secondary, radiationrelated malignancies $(9,16)$.

The controversies over radioiodine treatment of children/adolescents with DTC concern also the preparation for the therapy, e.g., the use of recombinant human TSH. Opponents of its use claim that it may result in decreased effectiveness of radioiodine treatment. However, in the literature there are no data to support or reject this assumption. In contrast to the large number of studies showing the efficacy of rhTSH preparations for adjuvant radioiodine treatment in adults with DTC, data for children and adolescents are scarce. There are only a few patients described in the literature so far $(11,13)$. To our best knowledge, our retrospective study is the first that evaluated different aspects of the rhTSH-aided radioiodine therapy procedure and its outcomes in children and adolescents with DTC.

The main goal of our study was to compare treatment procedures and disease outcomes after adjuvant radioiodine treatment performed either after endogenous (THW group) or after exogenous TSH (rhTSH group) stimulation. The definition of adjuvant treatment means that all detectable disease had been removed during surgery, and during the ${ }^{131}$ I treatment, patients were free of macroscopic disease as confirmed by neck ultrasound and radiological and scintigraphic examinations. In agreement with reports of highly successful rhTSH-aided adjuvant radioiodine treatment in adult patients $(1,21$, $22,23,24,25)$, we did not find any significant difference

Table 3 Reason for ${ }^{131}$ I retreatment in THW and rhTSH group.

\begin{tabular}{|c|c|c|c|}
\hline Reason for ${ }^{131}$ I retreatment & $\begin{array}{c}\text { All } \\
(n=130)\end{array}$ & $\begin{array}{c}\text { THW } \\
\text { group } \\
(n=83)\end{array}$ & $\begin{array}{l}\text { rhTSH } \\
\text { group } \\
(n=48)\end{array}$ \\
\hline $\begin{array}{l}\text { Thyroid bed uptake with } \\
\mathrm{Tg}<2 \mathrm{ng} / \mathrm{ml}\end{array}$ & $9(7 \%)$ & $5(\%)$ & $4(8 \%)$ \\
\hline $\mathrm{Tg}>2 \mathrm{ng} / \mathrm{ml}$ & $10(8 \%)$ & $7(7 \%)$ & $3(6 \%)$ \\
\hline Patients with $\mathrm{Tg}>2 \mathrm{ng} / \mathrm{ml}$ & $3(2 \%)$ & $3(4 \%)$ & 0 \\
\hline $\begin{array}{l}\text { Unequivocal results of } \\
\text { post-therapy }{ }^{131} \text { I scan }\end{array}$ & $4(3 \%)$ & $2(2 \%)$ & $2(4 \%)$ \\
\hline Late lung recurrence & $1(2 \%)$ & $1(2 \%)$ & 0 \\
\hline All & $27(21 \%)$ & $17(20 \%)$ & $10(20 \%)$ \\
\hline
\end{tabular}


in childhood/adolescent DTC outcomes after ${ }^{131}$ I treatments performed with exogenous or endogenous TSH stimulation. Of note, there was no difference in the rate of thyroid remnant ablation and biochemical (serum $\mathrm{Tg}$ concentration) remission after radioiodine treatment of DTC childhood/adolescent patients prepared either by administering rhTSH or by withholding levothyroxine for endogenous TSH stimulation. There were also no differences in the rate of structural disease recurrence. However, it is important to point out that the follow-up period is relatively short in the rhTSH group and a longer time is necessary to confirm these findings. Patients diagnosed with DTC may relapse as long as 30 years after primary treatment $(16,26,27)$, and in cases of cancer recurrence, they have a higher risk of death (27).

The only observed difference between the rhTSH and THW groups was a higher rate of TgAb positivity in the rhTSH group. However, a direct comparison is difficult as the method of assessment of $\mathrm{Tg}$ antibodies changed during the study period. Until 2006, we evaluated $\mathrm{Tg}$ antibodies indirectly, by the $\mathrm{Tg}$ recovery test with an institutional cut-off level of $70-130 \%$. Thereafter, direct $\mathrm{TgAb}$ measurement, with the lowest detection level of $10 \mathrm{IU} / \mathrm{ml}$, was introduced. The cut-off level of $10 \mathrm{IU} / \mathrm{ml}$ for direct $\mathrm{Tg}$ measurement is much more rigorous than our institutional Tg recovery limits. Therefore, we studied the results of these two methods separately. However, we observed a higher rate of $\mathrm{Tg}$ antibody positivity in the rhTSH group during ${ }^{131} \mathrm{I}$ treatment, regardless of the method of measurement used. This may be due to a shorter time between surgery and ${ }^{131} \mathrm{I}$ treatment in the rhTSH group (61 in the rhTSH vs 88 days in the THW group).

The success of radioiodine treatment can also be measured as the rate of ${ }^{131} \mathrm{I}$ retreatments. Although the decision to undergo a second course of ${ }^{131}$ I remained at the discretion of the treating physician, there was no difference between the THW and rhTSH group in the rates of retreatments. Of 130 patients, 23 (21\%) were referred for secondary radioiodine treatment. In a recent study by Mihailovic et al. (20), 43\% of paediatric patients treated with radioiodine after thyroxin withdrawal received at least two courses of ${ }^{131}$ I treatment; however, their study also included patients with metastatic disease.

In our study, we did not intend to evaluate the role of radioiodine treatment or prognosis of childhood/ adolescent DTC, as it was reported recently by several studies $(15,16,17,18,28)$. However, we have to underline here that the relatively low number $(3.8 \%)$ of disease recurrences is probably a result of not only extensive treatment of our study group but also our inclusion criteria. Only patients with adjuvant radioiodine treatment were included, and patients with persistent locoregional or distant metastases during ${ }^{131}$ I therapy were excluded.

Due to the retrospective nature of our study, patients did not complete any side effect-oriented questionnaires, yet in the medical records, we did not find any information on side effects such as headache or nausea, which have been reported by some paediatric DTC patients after rhTSH stimulation (29). We can only speculate that, due to the mild nature of the side effects, they were not reported during routine ward rounds. However, in one girl with disseminated DTC (a case not included in this study), a skin rash developed after rhTSH administration.

Use of rhTSH in preparation for radioiodine therapy has several advantages over thyroid hormone withdrawal. Recombinant human TSH-aided radioiodine treatment allows for lower radiation exposure of extrathyroidal compartments of the body during ${ }^{131}$ I therapy due to lower levels (about 30\% on average) of radioactivity in the blood. These findings can be explained by a non-disturbed renal clearance of radioiodine in the euthyroid state $(7,30,31)$. As a consequence of decreased whole body radiation exposure, at least in theory, there is a lower risk of secondary cancers after radioiodine therapy. This hypothesis is supported by a study showing that the rate of chromosomal translocation is significantly lower in radioiodine-treated patients after preparation with rhTSH than after THW (32). In our retrospective study, we did not have data on radiation exposure during rhTSH or THW preparation. However, we were able to compare the radiation dose rates at $1 \mathrm{~m}$, which may serve as a surrogate for radiation exposure of the patient. Although only borderline significant, the measurements performed $72 \mathrm{~h}$ after ${ }^{131} \mathrm{I}$ administration showed a tendency toward a lower dose rate in the rhTSH group. This finding supports the idea that rhTSH decreases radiation exposure to patients during rhTSH treatment.

An additional advantage of radioiodine treatment under recombinant TSH stimulation is the avoidance of hypothyroid morbidity. Although we did not have data to evaluate this aspect in our retrospective study, avoidance of hypothyroid morbidity is appealing in young, physically and mentally developing patients. Reductions in radiation exposure and avoidance of hypothyroid morbidity were the main reasons we decided to use rhTSH during radioiodine therapy because we were not able to be reimbursed for both therapy and diagnostic 
applications. It is only during the last 5 years that we have received sufficient funding to perform all TSH stimulation procedures in DTC children/adolescents with rhTSH.

Although our study showed that the results of adjuvant radioiodine treatment of childhood DTC did not depend on the type of TSH stimulation, this study had several limitations. This was a nonrandomised, uncontrolled retrospective study based on a medical charts review, and therefore, some aspects of rhTSH administration, e.g., side effects, might be underestimated. We cannot rule out selection bias toward THW preparation in patients with more advanced disease during surgical intervention. Additionally, the number of patients in the rhTSH group is rather low so one cannot exclude the possibility that a larger group of patients and a longer time of follow-up will show differences in outcomes between rhTSH and THW stimulation. Of note is also the fact that our study only evaluated selected cases without any evidence of persistent disease during ${ }^{131} \mathrm{I}$, so one cannot extend the results to more advanced cases.

\section{Conclusions}

In accordance with data from adults with DTC, our study findings demonstrated that in children and adolescents, rhTSH-aided adjuvant radioiodine treatment is associated with rates of scintigraphic thyroid ablation, biochemical remission, and short-term recurrence rates similar to traditional THW. As this preparation has several advantages over L-thyroxin withdrawal, rhTSH may become the preferred method of TSH stimulation once long-term follow-up demonstrates non-inferiority to THW in this age group.

\section{Supplementary data}

This is linked to the online version of the paper at http://dx.doi.org/10.1530/ EJE-15-0562.

\section{Declaration of interest}

Daria Handkiewicz-Junak, Jolanta Krajewska, and Barbara Jarzab received travel grants from Genzyme.

Funding

This research study did not receive any specific grant from any funding agency in the public, commercial, or not-for-profit sector.

\section{References}

1 Pacini F, Ladenson PW, Schlumberger M, Driedger A, Luster M, Kloos RT, Sherman S, Haugen B, Corone C, Molinaro E et al. Radioiodine ablation of thyroid remnants after preparation with recombinant human thyrotropin in differentiated thyroid carcinoma: results of an international, randomized, controlled study. Journal of Clinical Endocrinology and Metabolism 200691 926-932. (doi:10.1210/ jc.2005-1651)

2 Cooper DS, Doherty GM, Haugen BR, Kloos RT, Lee SL, Mandel SJ, Mazzaferri EL, McIver B, Pacini F, Schlumberger M et al. Revised American Thyroid Association management guidelines for patients with thyroid nodules and differentiated thyroid cancer. Thyroid 2009 19 1167-1214. (doi:10.1089/thy.2009.0110)

3 Mazzaferri EL \& Jhiang SM. Long-term impact of initial surgical and medical therapy on papillary and follicular thyroid cancer. American Journal of Medicine 199497 418-428. (doi:10.1016/0002-9343(94) 90321-2)

4 Sawka AM, Thephamongkhol K, Brouwers M, Thabane L, Browman G \& Gerstein HC. Clinical review 170: a systematic review and metaanalysis of the effectiveness of radioactive iodine remnant ablation for well-differentiated thyroid cancer. Journal of Clinical Endocrinology and Metabolism 200489 3668-3676. (doi:10.1210/jc.2003-031167)

5 Schlumberger M, Pacini F, Wiersinga WM, Toft A, Smit JW, SanchezFranco F, Lind P, Limbert E, Jarzab B, Jamar F et al. Follow-up and management of differentiated thyroid carcinoma: a European perspective in clinical practice. European Journal of Endocrinology 2004 151 539-548. (doi:10.1530/eje.0.1510539)

6 Dow KH, Ferrell BR \& Anello C. Quality-of-life changes in patients with thyroid cancer after withdrawal of thyroid hormone therapy. Thyroid 19977 613-619. (doi:10.1089/thy.1997.7.613)

7 Hänscheid H, Lassmann M, Luster M, Thomas SR, Pacini F, Ceccarelli C, Ladenson PW, Wahl RL, Schlumberger M, Ricard M et al. Iodine biokinetics and dosimetry in radioiodine therapy of thyroid cancer: procedures and results of a prospective international controlled study of ablation after rhTSH or hormone withdrawal. Journal of Nuclear Medicine 200647 648-654.

8 Remy H, Borget I, Leboulleux S, Guilabert N, Lavielle F, Garsi J, Bournaud C, Gupta S, Schlumberger M \& Ricard M. ${ }^{131}$ I effective halflife and dosimetry in thyroid cancer patients. Journal of Nuclear Medicine 200849 1445-1450. (doi:10.2967/jnumed.108.052464)

9 Francis G, Waguespack SG, Bauer AJ, Angelos P, Benvenga S, Cerutti J, Dinauer CA, Hamilton JK, Hay ID, Luster M et al. Management Guidelines for Children with Thyroid Nodules and Differentiated Thyroid Cancer The American Thyroid Association Guidelines Task Force on Pediatric Thyroid Cancer. Thyroid 201525 716-759. (doi:10.1089/thy.2014.0460)

10 Iorcansky S, Herzovich V, Qualey RR \& Tuttle RM. Serum thyrotropin (TSH) levels after recombinant human TSH injections in children and teenagers with papillary thyroid cancer. Journal of Clinical Endocrinology and Metabolism 200590 6553-6555. (doi:10.1210/jc.2005-1550)

11 Lau WF, Zacharin MR, Waters K, Wheeler G, Johnston V \& Hicks RJ. Management of paediatric thyroid carcinoma: recent experience with recombinant human thyroid stimulating hormone in preparation for radioiodine therapy. Internal Medicine Journal 200636 564-570. (doi:10.1111/j.1445-5994.2006.01149.x)

12 Ralli M, Cohan P \& Lee K. Successful use of recombinant human thyrotropin in the therapy of pediatric well-differentiated thyroid cancer. Journal of Endocrinological Investigation 200528 270-273. (doi:10.1007/BF03345384)

13 Rosario PW, Mineiro Filho AF, Lacerda RX \& Calsolari MR. Recombinant human TSH for thyroid remnant ablation with (131)I in children and adolescents with papillary carcinoma. Hormone Research in Paediatrics 201277 59-62. (doi:10.1159/000335088) 
14 Pacini F, Schlumberger M, Harmer C, Berg GG, Cohen O, Duntas L, Jamar F, Jarzab B, Limbert E, Lind P et al. Post-surgical use of radioiodine (131I) in patients with papillary and follicular thyroid cancer and the issue of remnant ablation: a consensus report. European Journal of Endocrinology 2005153 651-659. (doi:10.1530/eje.1.02014)

15 Enomoto Y, Enomoto K, Uchino S, Shibuya H, Watanabe S \& Noguchi S. Clinical features, treatment, and long-term outcome of papillary thyroid cancer in children and adolescents without radiation exposure. World Journal of Surgery 201236 1241-1246. (doi:10.1007/ s00268-012-1558-4)

16 Hay ID, Gonzalez-Losada T, Reinalda MS, Honetschlager JA, Richards ML \& Thompson GB. Long-term outcome in 215 children and adolescents with papillary thyroid cancer treated during 1940 through 2008. World Journal of Surgery 201034 1192-1202. (doi:10.1007/ s00268-009-0364-0)

17 Chow SM, Law SC, Mendenhall WM, Au SK, Yau S, Mang O \& Lau WH. Differentiated thyroid carcinoma in childhood and adolescenceclinical course and role of radioiodine. Pediatric Blood \& Cancer 200442 176-183. (doi:10.1002/pbc.10410)

18 Handkiewicz-Junak D, Wloch J, Roskosz J, Krajewska J, Kropinska A, Pomorski L, Kukulska A, Prokurat A, Wygoda Z \& Jarzab B. Total thyroidectomy and adjuvant radioiodine treatment independently decrease locoregional recurrence risk in childhood and adolescent differentiated thyroid cancer. Journal of Nuclear Medicine $2007 \mathbf{4 8}$ 879-888. (doi:10.2967/jnumed.106.035535)

19 Hänscheid H, Verburg FA, Biko J, Diessl S, Demidchik YE, Drozd V \& Reiners C. Success of the postoperative 131I therapy in young Belarusian patients with differentiated thyroid cancer after Chernobyl depends on the radiation absorbed dose to the blood and the thyroglobulin level. European Journal of Nuclear Medicine and Molecular Imaging 201138 1296-1302.

20 Mihailovic J, Nikoletic K \& Srbovan D. Recurrent disease in juvenile differentiated thyroid carcinoma: prognostic factors, treatments, and outcomes. Journal of Nuclear Medicine 201455 710-717. (doi:10.2967/ jnumed.113.130450)

21 Hugo J, Robenshtok E, Grewal R, Larson S \& Tuttle RM. Recombinant human thyroid stimulating hormone-assisted radioactive iodine remnant ablation in thyroid cancer patients at intermediate to high risk of recurrence. Thyroid 201222 1007-1015. (doi:10.1089/thy.2012. 0183)

22 Tuttle RM, Lopez N, Leboeuf R, Minkowitz SM, Grewal R, Brokhin M, Omry G \& Larson S. Radioactive iodine administered for thyroid remnant ablation following recombinant human thyroid stimulating hormone preparation also has an important adjuvant therapy function. Thyroid 201020 257-263. (doi:10.1089/thy.2009.0401)

23 Tuttle RM, Brokhin M, Omry G, Martorella AJ, Larson SM, Grewal RK, Fleisher M \& Robbins RJ. Recombinant human TSH-assisted radioactive iodine remnant ablation achieves short-term clinical recurrence rates similar to those of traditional thyroid hormone withdrawal. Journal of Nuclear Medicine 200849 764-770. (doi:10.2967/jnumed.107.049072)

$24 \mathrm{Tu}$ J, Wang S, Huo Z, Lin Y, Li X \& Wang S. Recombinant human thyrotropin-aided versus thyroid hormone withdrawal-aided radioiodine treatment for differentiated thyroid cancer after total thyroidectomy: a meta-analysis. Radiotherapy and Oncology 2014110 25-30. (doi:10.1016/j.radonc.2013.12.018)

25 Barbaro D, Grosso M, Boni G, Lapi P, Pasquini C, Orsini P, Turco A, Meucci G, Marzola MC, Berti P, Rubello D et al. Recombinant human TSH and ablation of post-surgical thyroid remnants in differentiated thyroid cancer: the effect of pre-treatment with furosemide and furosemide plus lithium. European Journal of Nuclear Medicine and Molecular Imaging 201037 242-249. (doi:10.1007/s00259-009-1254-2)

26 Fareau GG \& Vassilopoulou-Sellin R. Late disease recurrence in patients diagnosed with and treated for differentiated thyroid carcinoma. Endocrinologist 200616 329-334. (doi:10.1097/01.ten.0000246091. 09709.59)

27 Landau D, Vini L, A'Hern R \& Harmer C. Thyroid cancer in children: the Royal Marsden Hospital experience. European Journal of Cancer 2000 36 214-220. (doi:10.1016/S0959-8049(99)00281-6)

28 Borson-Chazot F, Causeret S, Lifante JC, Augros M, Berger N \& Peix JL. Predictive factors for recurrence from a series of 74 children and adolescents with differentiated thyroid cancer. World Journal of Surgery 200428 1088-1092. (doi:10.1007/s00268-004-7630-y)

29 Luster M, Handkiewicz-Junak D, Grossi A, Zacharin M, Taïeb D, Cruz O, Hitzel A, Casas JA, Mäider U \& Dottorini ME. Recombinant thyrotropin use in children and adolescents with differentiated thyroid cancer: a multicenter retrospective study. Journal of Clinical Endocrinology and Metabolism 200994 3948-3953. (doi:10.1210/jc.2009-0593)

30 Loffler M, Weckesser M, Franzius C, Kies P \& Schober O. Iodine excretion during stimulation with rhTSH in differentiated thyroid carcinoma. Nuklearmedizin $2003 \mathbf{4 2}$ 240-243.

31 Luster M, Sherman SI, Skarulis MC, Reynolds JR, Lassmann M, Hänscheid H \& Reiners C. Comparison of radioiodine biokinetics following the administration of recombinant human thyroid stimulating hormone and after thyroid hormone withdrawal in thyroid carcinoma. European Journal of Nuclear Medicine and Molecular Imaging 200330 1371-1377. (doi:10.1007/s00259-003-1230-1)

32 Frigo A, Dardano A, Danese E, Davì MV, Moghetti P, Colato C, Francia G, Bernardi F, Traino C, Monzani F et al. Chromosome translocation frequency after radioiodine thyroid remnant ablation: a comparison between recombinant human thyrotropin stimulation and prolonged levothyroxine withdrawal. Journal of Clinical Endocrinology and Metabolism 200994 3472-3476. (doi:10.1210/ jc.2008-2830)

Received 6 June 2015

Revised version received 31 August 2015

Accepted 30 September 2015 